\title{
Cost-effectiveness of birth-dose hepatitis B vaccination among refugee populations in the African region: a series of case studies
}

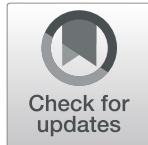

Joseph Michael Reardon ${ }^{1 *}$ D, Siobhán M. O'Connor ${ }^{2}$, Joseph D. Njau ${ }^{3}$, Eugene K. Lam ${ }^{4}$, Catherine A. Staton ${ }^{5}$ and Susan T. Cookson ${ }^{6}$

\begin{abstract}
Background: Hepatitis B affects 257 million people worldwide. Mother-to-child hepatitis B virus (HBV) transmission is a preventable cause of substantial morbidity and mortality and poses greatest risk for developing chronic HBV infection. The World Health Organization recommends that all countries institute universal hepatitis B birth dose $(H e p B B D)$ vaccination during the first $24 \mathrm{~h}$ of life, followed by timely completion of routine immunization. The objective of this analysis was to assess the cost-effectiveness of adding HepB BD vaccination among sub-Saharan African refugee populations where the host country's national immunization policy includes HepB BD.
\end{abstract}

Methods: We performed a cost-effectiveness analysis of three hepatitis B vaccination strategy scenarios for campbased refugee populations in the African Region (AFR): routine immunization (RI), RI plus universal HepB BD, and RI plus HepB BD only for newborns of hepatitis B surface antigen-positive mothers identified through rapid diagnostic testing (RDT). We focused analyses on refugee populations living in countries that include HepB BD in national immunization schedules: Djibouti, Algeria and Mauritania. We used a decision tree model to estimate costs of vaccination and testing, and costs of life-years lost due to complications of chronic hepatitis B.

Results: Compared with Rl alone, addition of HepB BD among displaced Somali refugees in Djibouti camps would save 9807 life-years/year, with an incremental cost-effectiveness ratio (ICER) of 0.15 USD (US dollars) per life-year saved. The RI plus HepB BD strategy among Western Saharan refugees in Algerian camps and Malian refugees in Mauritania camps would save 27,108 life-years/year with an ICER of 0.11 USD and 18,417 life-years/year with an ICER of 0.16 USD, respectively. The RI plus RDT-directed HepB BD was less cost-effective than RI plus delivery of universal HepB BD vaccination or Rl alone.

Conclusions: Based on our model, addition of HepB BD vaccination is very cost-effective among three sub-Saharan refugee populations, using relative life-years saved. This analysis shows the potential benefit of implementing HepB BD vaccination among other camp-based refugee populations as more AFR countries introduce national HepB BD policies.

Keywords: Hepatitis B, refugee, Africa, cost-effectiveness, Djibouti, Algeria, Mauritania, Somalia, Western Sahara, Mali

\footnotetext{
* Correspondence: Joseph_Reardon@post.harvard.edu

'Department of Emergency Medicine, Greenville Health System, 701 Grove

Rd, Greenville, SC 29605, USA

Full list of author information is available at the end of the article
}

(c) The Author(s). 2019 Open Access This article is distributed under the terms of the Creative Commons Attribution 4.0 International License (http://creativecommons.org/licenses/by/4.0/), which permits unrestricted use, distribution, and reproduction in any medium, provided you give appropriate credit to the original author(s) and the source, provide a link to the Creative Commons license, and indicate if changes were made. The Creative Commons Public Domain Dedication waiver (http://creativecommons.org/publicdomain/zero/1.0/) applies to the data made available in this article, unless otherwise stated. 


\section{Background}

Hepatitis B virus (HBV) infection is a major cause of preventable morbidity and mortality, affecting 257 million people and causing approximately 887,000 deaths annually worldwide [1]. In nations with high rates of chronic HBV infection, transmission of $\mathrm{HBV}$ from mother-to-child poses the greatest risk for developing chronic hepatitis B [2]. Unlike other major infectious diseases, deaths from HBV infection are entirely preventable by low-cost vaccination prior to exposure. Delivery of the hepatitis B (HepB BD) around birth followed by timely completion of the routine hepatitis $\mathrm{B}$ vaccine series can prevent $85-95 \%$ of $\mathrm{HBV}$ transmission, and is recommended by World Health Organization (WHO) [3, 4].

Displaced persons, such as refugees in humanitarian emergencies, are particularly susceptible to HBV transmission because of higher baseline rates of chronic HBV infection, with an average of $7.2 \%$ of all refugees having Hepatitis B surface antigen (HBsAg) seropositivity [5]. Establishment of supplemental immunization against rapidly fatal diseases, with routine immunization (RI) established as soon as possible, are among the first interventions advised in refugee situations [6, 7]. No prior studies have examined the cost-effectiveness of HepB $B D$ vaccination among such displaced populations.

WHO recommends that all countries institute universal HepB BD delivery during the first $24 \mathrm{~h}$ of life, followed by timely completion of routine immunization [2]. In sub-Saharan Africa (SSA), HepB BD vaccination has been gradually adopted by national Ministries of Health, with WHO targeting universal adoption by 2020 [8]. Three refugee populations are benefitting from HepB BD vaccination in their host countries: Somali refugees in Djibouti, Malian refugees in Mauritania, and Western Saharan refugees in Algeria. In each of these cases, the refugee population did not have access to HepB BD vaccination in the country of origin but their newborns are receiving the $\mathrm{HepB} B \mathrm{BD}$ vaccine due to adoption of a universal HepB BD vaccine policy in the host country [9].

These refugee populations have suffered years of uncertainty. Somali refugees have been displaced to Djibouti for decades, fleeing chronic civil war between the weak central government and separatist insurgents [10]. Somali refugees occupy two major camps in Djibouti, relying on Djibouti's relative stability compared with its neighbors. Malian refugees have faced a similar struggle, displaced primarily into a single refugee camp in Mauritania after fleeing chronic attacks by disparate desert terrorist organizations that have failed to honor international peace agreements [11]. Refugees from Western Sahara have faced a slightly different situation, having crossed into Algeria to escape decades of conflict between the separatist Polisario movement and the Moroccan government, which claims the territory of Western Sahara [12].
The objective of this analysis was to determine the health impact and cost-effectiveness of RI plus universal HepB BD, or alternatively using a rapid diagnostic test (RDT) for maternal HBsAg to guide $\mathrm{HepB} B D$ vaccination, for these three refugee populations in SSA.

\section{Methods \\ Model cohorts and immunization strategies}

We examined African countries with existing national HepB BD vaccination policy, and then selected countries hosting large and protracted refugee populations in established camps [13]. We calculated the estimated annual birth cohort for each identified refugee population by multiplying the camp size by the crude birth rate from the country of origin. For each population, we compared life-years lost based on our decision tree model and the cost for each of three strategies for implementation of HepB BD: RI, RI plus universal HepB BD, and RI plus HepB BD provided only for newborns of HBsAg-positive mothers identified through RDT for HBsAg (RDT-directed HepB BD plus RI).

\section{Model design}

We adapted the disease-specific decision-tree models of $\mathrm{Lu}$, et al. and $\mathrm{Tu}$, et al. to estimate the impact and cost-effectiveness of implementing HepB BD by comparing the cost of adding that intervention with life-years lost due to complications of chronic hepatitis $\mathrm{B}$ in the refugee camp setting $[14,15]$. We constructed the model using TreeAge Pro 2017 (Williamstown, Massachusetts, USA). Variables considered in the analysis are listed in Table 1 . The model inputs include mortality due to either HBV-associated cirrhosis or hepatocellular carcinoma (HCC); we did not include fulminant $\mathrm{HBV}$ infection at time of acquisition. Additional variables included combined RI and HepB BD vaccine coverage and efficacy, and cost (administrative vaccine purchase and HBsAg RDT). We incorporated population-specific values for vaccine coverage in host country, HBsAg prevalence and fertility rate (but substituting Morocco for Western Sahara due to lack of data), and camp size for refugee camps in Djibouti, Mauritania and Algeria using published figures as shown in Table 1 [10, 12, 16-20]. We did not consider direct medical costs for other complications of hepatitis B because access to medical care is limited in these settings and the likelihood of obtaining prolonged treatment for complications is low.

\section{Disease progression}

Our decision tree simulated the vaccination strategies, using maternal HBsAg rate (but substituting Morocco for Western Sahara due to lack of data) as a proxy for HBV prevalence, and calculating probabilities of infant infection based on vaccination coverage and efficacy (Fig. 1). We 
Table 1 Parameter values used in the decision tree model and sensitivity analysis

\begin{tabular}{|c|c|c|c|}
\hline Parameter & Base case estimate & Sensitivity range & References \\
\hline \multicolumn{4}{|l|}{ Epidemiologic } \\
\hline \multicolumn{4}{|l|}{ Camp size [2015] } \\
\hline Djibouti [destination from Somalia] & 22,080 & NA & [10] \\
\hline Algeria [destination from Sahara] & 90,000 & NA & [12] \\
\hline Mauritania [destination from Mali] & 48,000 & NA & [11] \\
\hline \multicolumn{4}{|l|}{ Crude Birth Rate (births per 1000 per year) [2015] } \\
\hline Somalia [country of origin] & 44 & NA & [20] \\
\hline Western Sahara [region of origin] & 20 & NA & {$[20]$} \\
\hline Mali [country of origin] & 44 & NA & [20] \\
\hline \multicolumn{4}{|c|}{ Camp-based Birth cohort per year (Camp size x Crude Birth Rate) } \\
\hline Djibouti & 972 & NA & \\
\hline Algeria & 1800 & NA & \\
\hline Mauritania & 2112 & NA & \\
\hline \multicolumn{4}{|l|}{ Average life expectancy [2015] } \\
\hline Somalia [country of origin] & 56 & NA & [29] \\
\hline Morocco [nearest to Western Sahara] & 74 & NA & [29] \\
\hline Mali [country of origin] & 58 & NA & [29] \\
\hline \multicolumn{4}{|l|}{ Population proportion who are $\mathrm{HBsAg}+$} \\
\hline Somalia & 0.1477 & $0.1377-0.1584(95 \% \mathrm{Cl})$ & {$[52]$} \\
\hline Morocco [substituted for Western Sahara] & 0.0109 & $0.0105-0.0114(95 \% \mathrm{Cl})$ & {$[52]$} \\
\hline Mali & 0.1307 & $0.1269-0.1347(95 \% \mathrm{Cl})$ & {$[52]$} \\
\hline \multicolumn{4}{|l|}{ Transmission rate } \\
\hline Perinatal transmission in chronic infected mother & 0.91 & NA & [24] \\
\hline \multicolumn{4}{|l|}{ Disease progression, $\%$} \\
\hline HBV carrier to chronic infection & 0.073 & $0.003-0.073^{*}$ & [25] \\
\hline Chronic hepatitis B to HBV carrier & 0.17 & 0.105-0.306 (Assumed max) & [25] \\
\hline Chronic hepatitis B to compensated cirrhosis & 0.129 & $0.004-0.153$ & [53] \\
\hline Chronic hepatitis B to hepatocellular carcinoma (HCC) & 0.005 & $0.002-0.007$ & [25] \\
\hline Compensated cirrhosis to decompensated cirrhosis & 0.054 & $0.028-0.1$ & [25] \\
\hline Compensated cirrhosis to HCC & 0.03 & $0.01-0.1$ & [27] \\
\hline \multicolumn{4}{|l|}{ Mortality rate } \\
\hline Background mortality & Country-specific tables & & [28] \\
\hline Compensated cirrhosis & 0.037 & $0.03-0.044$ & [53] \\
\hline Decompensated cirrhosis & 1 & 0.9-1 (Assumed, $-10 \%)$ & Assumed \\
\hline $\mathrm{HCC}$ & 1 & $0.9-1$ (Assumed, $-10 \%)$ & [53] \\
\hline \multicolumn{4}{|l|}{ Clinical interventions } \\
\hline \multicolumn{4}{|l|}{ Vaccine coverage (Hepatitis B, 3 doses) [2015] } \\
\hline Djibouti & 0.78 & $0.63-1(-25 \% \text { to } 1)^{*}$ & [15] \\
\hline Algeria & 0.95 & $0.73-1(-25 \% \text { to } 1)^{*}$ & {$[15]$} \\
\hline Mauritania & 0.73 & $0.55-1(-25 \% \text { to } 1)^{*}$ & [15] \\
\hline \multicolumn{4}{|l|}{ Vaccine protection, $\%$} \\
\hline Birth dose + Routine Immunization (RI) & 0.953 & $0.946-0.960(95 \% \mathrm{Cl})$ & {$[30]$} \\
\hline $\mathrm{Rl}$ & 0.722 & $0.676-.765(95 \% \mathrm{Cl})$ & {$[30]$} \\
\hline
\end{tabular}


Table 1 Parameter values used in the decision tree model and sensitivity analysis (Continued)

\begin{tabular}{|c|c|c|c|}
\hline Parameter & Base case estimate & Sensitivity range & References \\
\hline Residual Susceptibility in Immunologic Failure & 0.05 & $\begin{array}{l}0.0375-0.0625 \\
(+/-25 \%)\end{array}$ & [34] \\
\hline \multicolumn{4}{|l|}{ Economic [2015 USD] } \\
\hline UNICEF price per dose & 0.173 & NA & [54] \\
\hline Operational costs per dose or test & 0.93 & $\begin{array}{l}0.11-2.00^{*} \\
\text { (Assumed max) }\end{array}$ & {$[26,44]$} \\
\hline Cost per rapid diagnostic test (RDT) & 0.50 & NA & {$[55]$} \\
\hline Sensitivity of RDT (pooled) & 0.948 & $0.946-0.960$ & {$[32]$} \\
\hline Specificity of RDT (pooled) & 0.995 & $0.993-1$ & [32] \\
\hline
\end{tabular}

*Sensitivity range used in Monte Carlo simulation

Abbreviations: $H B s A g$ hepatitis B virus surface antigen, $H B V$ hepatitis B virus, $H C C$ hepatocellular carcinoma, RDT rapid diagnostic test

used a Markov cohort model, cycling yearly, to model hepatitis B progression (Fig. 2). The analytic horizon was from birth to death. We used a global discounting rate of 3\% [21]. We modeled four states, with HBV inactive carrier status and chronic active hepatitis B moving between each other at fixed probabilities, chronic hepatitis capable of progressing to compensated cirrhosis or $\mathrm{HCC}$, and compensated cirrhosis able to progress to decompensated cirrhosis or HCC. Chronic hepatitis is defined as persistent hepatic inflammation, whereas cirrhosis is defined as liver fibrosis affecting the liver's synthetic functioning [22]. Compensated cirrhosis is defined as fibrosis with liver dysfunction that does not substantially impair the individual's daily activity, whereas decompensated cirrhosis encompasses gastrointestinal bleeding, encephalopathy and massive ascites that are clinically apparent and usually fatal in the short term
[23]. Transition probabilities of movement from one state to another during hepatitis $B$ infection were based on published literature [24-27].

\section{Input parameters}

For birth rate, life expectancy and HBSAg prevalence, we used the country of origin of the refugees, except for life expectancy from Western Sahara because the measure was not available; the estimate for Morocco was substituted. We obtained life expectancies from the World Bank and age-specific background mortality rates and vaccine coverage data from WHO tables [16, 28, 29].

To approximate the vaccine efficacy of RI plus universal HepB BD versus RI alone, we applied figures from a retrospective study of vaccine efficacy for preventing vertical transmission of HBV infection in Canada, comparing $\mathrm{HBsAg}$ prevalence rates among children who

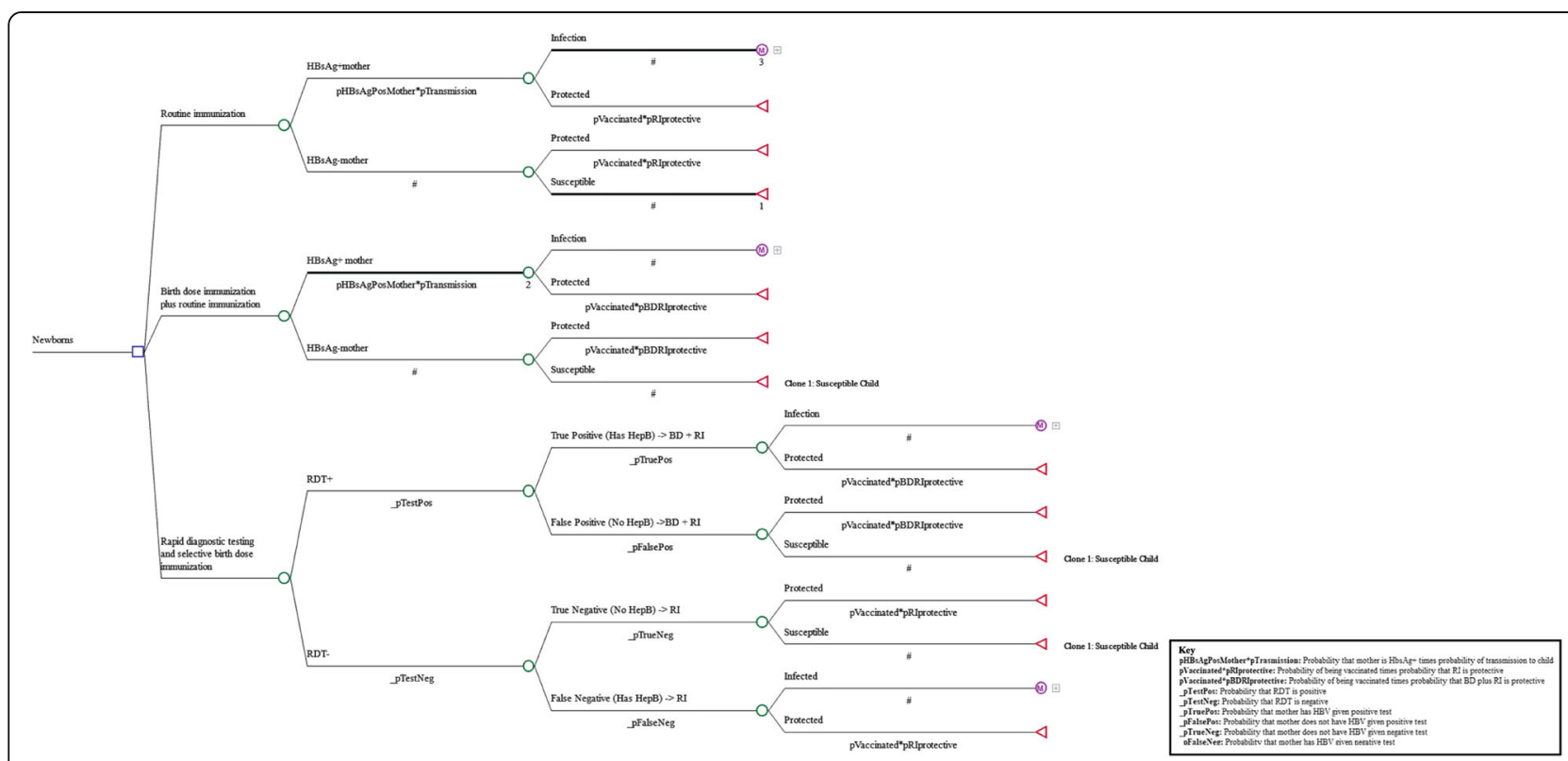

Fig. 1 Decision tree modeling probabilities of hepatitis B vertical transmission in three hepatitis B immunization scenarios 


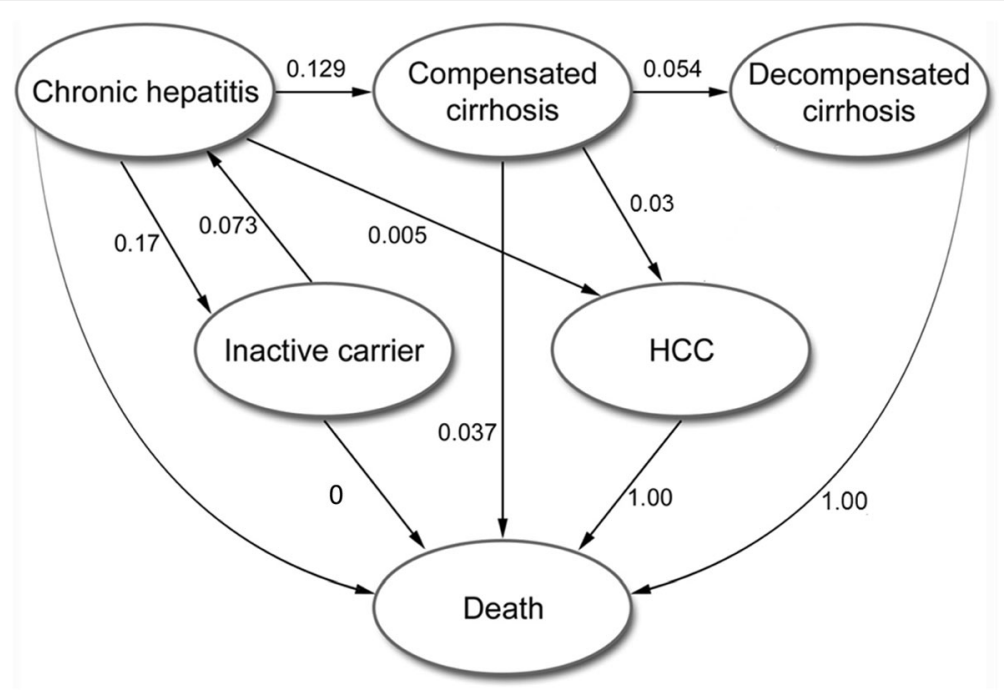

Fig. 2 Simplified model of hepatitis B virus infection natural history. Numbers indicate transition probabilities between each state

were vaccinated within 3 days of birth to those who were vaccinated more than 8 days after birth [30].

\section{Cost}

We used UNICEF prices for multi-dose monovalent hepatitis $B$ vaccine (HepB BD), and program costs (vaccine purchase, injection supplies, vaccine distribution and service delivery) from a similar study in the Gambia, updating for inflation $[26,31]$. We chose cost of the highly sensitive and specific Alere Determine ${ }^{\text {Tx }}$ HBsAg test (Waltham, MA), widely available in Africa, to represent HBsAg RDT [32].

We assumed RI costs in all countries were from government perspective. Costs of implementing HepB BD delivery were therefore calculated from the public payer perspective (i.e., the cost to the government to procure and deliver the vaccine).

\section{Model Assumptions}

Our model has several key assumptions.

On the public health level, we assumed that infants would receive $\mathrm{HepB} B D$ vaccination at the same rate as RI and all receiving HepB BD would go on to receive RI, as they receive health services within the camp setting. We varied this assumption by a margin of - $25 \%$ of estimate to $100 \%$ in the sensitivity analysis [33]. We assumed that the operational costs for performing RDT were similar to the operational costs for delivery of HepB BD vaccine as they both require trained fieldworkers, supplies and transport, and we varied this assumption in the sensitivity analysis as exact operational costs for RDT are not available. We assumed that external stressors are approximately equal between camps as all refugee camps in this analysis are supervised by the United Nations High Commissioner for Refugees. We used a residual susceptibility rate of $5 \%$ for likelihood of acquiring hepatitis B horizontally in the event of immunologic failure [34].

For disease-specific variables, we made several simplifying assumptions about disease progression to facilitate demonstration of the model. We assumed that all mother-to-child HBV transmission happened in the perinatal period, as prior studies have shown that later vertical transmission is less than or equal to $1 \%[35,36]$. We did not calculate disability-adjusted life years (DALYs) lost or incidental costs to families or communities as the progression from fulminant disease (decompensated cirrhosis or HCC) to death is likely rapid (within one year) in the absence of dedicated health services as shown in the literature $[37,38]$. A recent study supported this assumption, finding that globally, years of life lost due to hepatitis make up $98 \%$ of the burden of the disease encapsulated by disability-adjusted life years (DALYs) [39].

We assumed that infants did not die from fulminant hepatitis $\mathrm{B}$, as the rate of death from perinatal hepatitis is low (less than 1 in 1000) [40]. We used overall HBV transmission rates from an HBV-infected mother (both hepatitis $\mathrm{B}$ e antigen-positive and -negative) to her child from the literature [24]. We also did not include the effect of co-infection with HIV as reported HIV rates in the studied areas are low enough $(0.1$ to $1.6 \%)$ to not significantly alter the results of our model [41].

\section{Outcome measures}

We compared number of life-years lost from HBV attributable HCC- and cirrhosis-related premature death among the RI, RI plus universal HepB BD, and RDT-directed HepB BD plus RI scenarios and calculated cost per life year saved and incremental cost-effectiveness ratio (ICER) under each scenario. 


\section{Parameter uncertainty}

We conducted one-way sensitivity analyses, varying the parameters one by one with the range of values shown in Table 1. To estimate the prevalence of HBsAg prevalence in refugee populations, we used sources from the published literature [42] and examined sensitivity around these values.

To determine the sensitivity around estimates of stochastic variables, we performed a second-order Monte Carlo simulation with 1000 iterations. We varied vaccination coverage, probability of $\mathrm{HBV}$ carriers transitioning to chronic hepatitis, cirrhosis and HCC, and the cost of operations according to triangular distributions, with the lower and upper bounds of vaccination coverage representing the worst and best performing countries in the African region [43]. We varied the transition to complications probability bounds by $25 \%$, and varied the operational cost, with the lower bound representing the lowest estimate for the percentage of operational cost relative to vaccine cost determined by the Expanded Program on Immunization Costing study [44], and the upper bound of operational cost varied upward to 2 USD to account for vaccine deployment during rainy season or extreme condition. We assumed a fixed cost for the vaccine and RDT.

\section{Results}

\section{Impact of vaccination}

The impact of HepB BD vaccination was similar across multiple camp situations; it would save 506 life-years per
10,000 refugees per year among refugees in Djibouti, 126 life-years per 10,000 refugees per year among refugees in Algeria, and 2204 life-years per 10,000 refugees per year among refugees in Mauritania (Table 2).

\section{Cost-effectiveness}

The Monte Carlo simulations showed a trend toward increased effectiveness as cost increased, but a relative ceiling of effectiveness was seen despite increasing cost when the proportion of children receiving RI approached 1.

In each case, the cost per year of life saved by addition of HepB BD is much less than the average gross domestic product (GDP) of the host country (0.83 USD versus 3342 USD in Djibouti, 1.59 USD versus 14,613 USD in Algeria and 0.18 USD versus 3835 USD in Mauritania) [45]. In all countries, RDT-directed HepB plus RI was less cost-effective than RI alone or RI plus universal HepB BD.

\section{Sensitivity analysis}

Using triangular probability distributions, we found that none of the confidence intervals around transition probabilities in the Markov model affected the final cost, effectiveness, or ICER by more than $2 \%$ in any analysis. In sensitivity analyses, the baseline vaccination rate had the greatest impact on net health benefit. For each country, net life years gained varied across a range of 2.1 to 2.4 years when considering a $-25 \%$ of estimate to $100 \%$ in baseline vaccination rate. Variance in protection of RI plus universal HepB BD against HBV infection was the second greatest contributor to uncertainty in net

Table 2 Health and cost outcomes of one-year refugee birth cohorts under different hepatitis B vaccine immunization scenarios for refugees resettled from Western Sahara to Algeria, Somalia to Djibouti and Mali to Mauritania [24, 41, 54, 55]

\begin{tabular}{|c|c|c|c|c|}
\hline Strategy & $\begin{array}{l}\text { Relative Life-Years } \\
\text { Saved per Camp }\end{array}$ & $\begin{array}{l}\text { Life-Years Saved per } \\
10,000 \text { Refugees }\end{array}$ & $\begin{array}{l}\text { Vaccine and Program Costs } \\
\text { (USD) per Camp }\end{array}$ & $\begin{array}{l}\text { Incremental Cost } \\
\text { (USD) per Camp }\end{array}$ \\
\hline \multicolumn{5}{|l|}{ Djibouti } \\
\hline Routine immunization & - & & 3460 & - \\
\hline Birth dose plus routine immunization & 1118 & 506 & 4393 & 933 \\
\hline $\begin{array}{l}\text { Rapid diagnostic testing plus birth dose } \\
\text { and routine immunization }\end{array}$ & 807 & 365 & 4471 & 1011 \\
\hline \multicolumn{5}{|l|}{ Algeria } \\
\hline Routine immunization & - & & 6408 & - \\
\hline Birth dose plus routine immunization & 1134 & 126 & 8208 & 1800 \\
\hline $\begin{array}{l}\text { Rapid diagnostic testing plus birth dose } \\
\text { and routine immunization }\end{array}$ & 180 & 20 & 8172 & 1764 \\
\hline \multicolumn{5}{|l|}{ Mauritania } \\
\hline Routine immunization & - & & 7519 & - \\
\hline Birth dose plus routine immunization & 10,581 & 2204 & 9420 & 1901 \\
\hline $\begin{array}{l}\text { Rapid diagnostic testing plus birth dose } \\
\text { and routine immunization }\end{array}$ & 9905 & 2064 & 9567 & 2049 \\
\hline
\end{tabular}


12.00

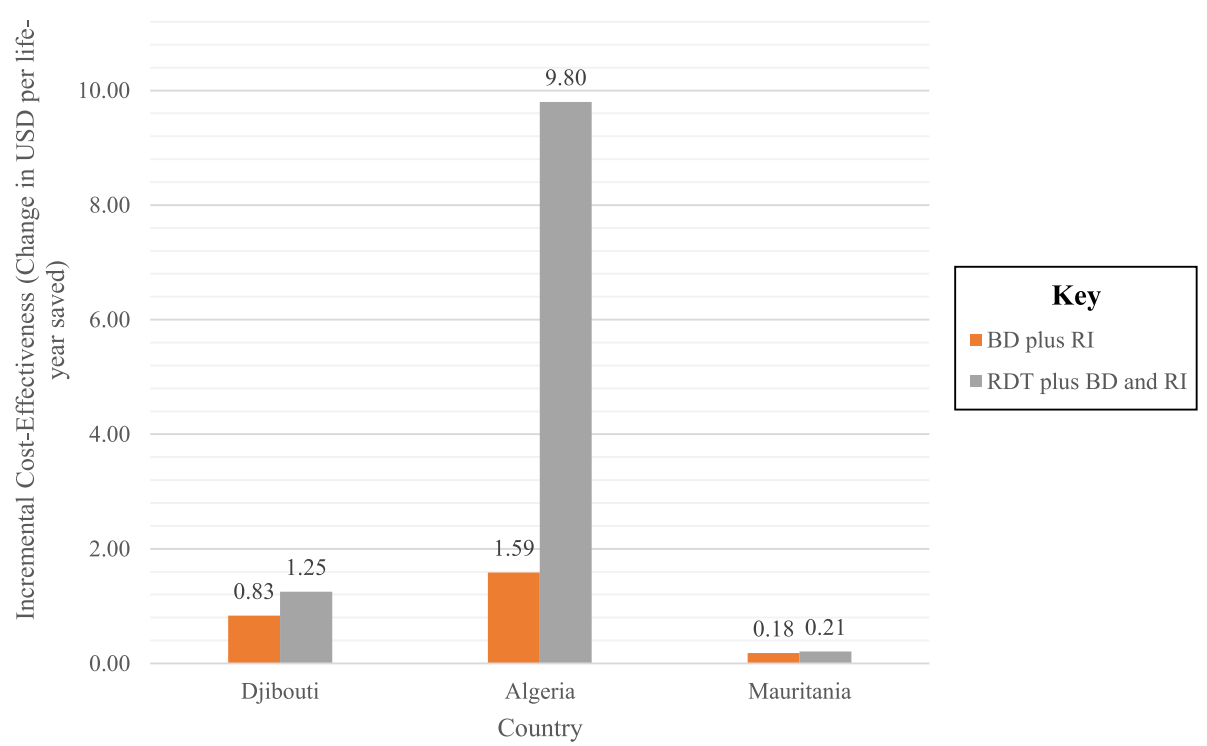

Fig. 3 Incremental cost-effectiveness ratios of adding hepatitis B vaccine birth dose (HepB BD) to routine immunization (RI) or RI plus HepB BD delivery only to newborns of HBV-infected mothers diagnosed by rapid diagnostic testing for hepatitis B surface antigen, compared to RI alone among camp-based refugees resettled from Western Sahara to Algeria, from Somalia to Djibouti and from Mali to Mauritania

benefits, given the uncertainty of protection from prior studies [30]. The ICER was more favorable for RI plus universal HepB BD than for a test and treat strategy (Fig. 3). The incremental cost-effectiveness of RI plus universal HepB BD over RI alone was most affected by the probability that RI is protective against hepatitis $\mathrm{B}$. The greatest variability in net benefits upon sensitivity analysis was seen in the Mauritanian refugee population (Fig. 4). Sensitivity analyses were similar for all countries.

In the Monte Carlo simulation, we observed overlap in both cost and effectiveness for all three approaches, although RI plus universal HepB BD was both more effective and more cost-effective in terms of dollars spent per year of life saved than either RI alone or RDT-directed HepB plus RI under most scenarios. All approaches remained very cost-effective under all simulated scenarios.

\section{Discussion}

The combination of RI plus universal HepB BD was very cost-effective for the three refugee populations analyzed, based on the criterion that an intervention must cost less than the annual GDP per capita of the region of interest [46]. Each of the host countries studied has begun to implement universal HepB BD vaccination [9], and our results show that this strategy should provide considerable benefit to the refugee populations of these regions, with a net 55,332 life years saved per year. However, the total life-years saved per 10,000 refugees for Somalian and Malian refugees were higher than the total for Western Saharan refugees, reflecting those countries' larger prevalence of HBsAg positive mothers. Use of RDT-directed HepB plus RI was also found to be cost-effective, but the savings were inferior to RI plus universal HepB BD vaccination both in incremental cost-effectiveness and in relative life-years saved.

HepB BD vaccination has been found to be very cost-effective in nearly every other situation in which it has been studied, including in low-resource and high-resource settings $[15,26,47]$. Cost-effectiveness in prior studies was only reduced in situations in which baseline maternal HBV prevalence was very low, which is unlikely in these refugee camps given the nearly universally high prevalence of HBsAg seropositivity reported across refugee populations [5, 48]. However, refugee camps often present a different set of health priorities and more pressing needs, such as water, food or safety may temporarily overshadow vaccination, especially with new and underutilized vaccines [6]. Our results suggest that HepB BD vaccination must remain among the top priorities in refugee camps.

Refugee camps also represent a unique situation for global health, as some refugees are in the process of being resettled to a third asylum country. In 2014 alone, over 73,000 refugees were resettled, the majority of them moving to North America, Australia and the Nordic countries [49]. The program cost calculated here for all of the target refugee camps is less than the cost for treatment of a single episode of decompensated cirrhosis or HCC in a wealthier country. Our findings highlight that investment in health services in refugee camps and 


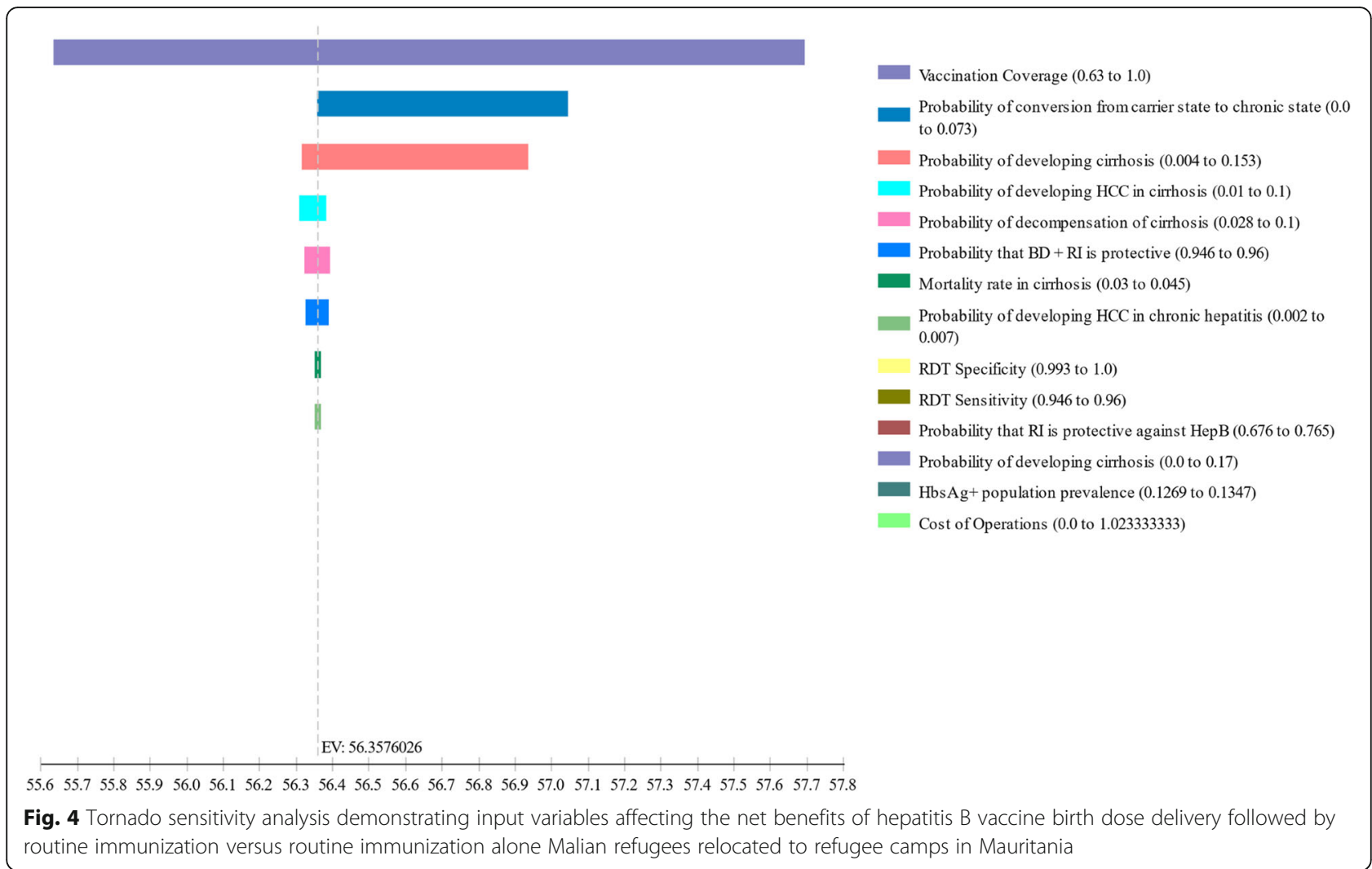

host communities themselves are likely to yield great benefits at low cost.

Our sensitivity analysis shows that the two main factors affecting the incremental cost-effectiveness of HepB BD vaccination are vaccine coverage and vaccine efficacy. Data from early clinical trials of HepB BD vaccination show substantial improved protection and it would be unethical to conduct further randomized trials $[4,24]$. The only semi-randomized study demonstrating vaccine efficacy was under-powered and limited by methodological limitations [3]. Improving HepB BD coverage rates is the best way to maximize benefit from this intervention.

Global increases in vaccination have been one of the great success stories of the modern era. The advent of monitoring and reporting of vaccination rates has been coupled with steady improvement in vaccination rates in almost every country $[33,43]$. Other means of improving vaccine uptake, including market-based approaches and multilateral partnerships, have been considered but inconsistently applied [50]. We expect that the advent of reporting of $\mathrm{HepB} \mathrm{BD}$ vaccination rates in refugee camps along with concomitant health systems strengthening would catalyze continued improvements. This health system strengthening among a displaced population will not only benefit the refugees but also add to overall global health security.
The cost-effectiveness modeling used here employs existing data in the literature on both the natural history of perinatal-transmitted HBV and current vaccination costs. Such modeling can be easily and flexibly applied to other new and underutilized vaccines such as rotavirus, rubella, typhoid fever, rabies, and human papillomavirus in order to help create an evidence base for prioritizing each intervention in refugee settings [51].

\section{Limitations}

This analysis has several limitations. Firstly, our probability point estimates for disease modelling and cost were drawn from existing literature and may not necessarily reflect the populations under study. We used a static model that does not incorporate horizontal transmission of HBV, which limits our ability to calculate life-years saved through protection from post-perinatal transmission. However, the benefits of RI to protect against horizontal transmission of $\mathrm{HBV}$ are already well-known [52]. We assumed that all refugees receiving HepB BD vaccination would receive RI, which may be interrupted in unstable situations. It is also possible that refugees may not accept vaccination due to cultural reasons or the perception that complications of hepatitis are too far in the future to warrant preventive measures now. We attempted to account for this possibility through the sensitivity analysis around actual vaccination 
rates in our model. [33], which is why we used the lower of the two estimates of vaccine coverage in order to generate a more conservative model.

We made several simplifying assumptions about the natural history of HBV infection, including a 100\% one-year mortality rate for patients diagnosed with $\mathrm{HCC}$ and presuming that $\mathrm{HCC}$ is non-treatable [53]. The survival rates of patients with decompensated cirrhosis and HCC are unknown among populations with limited access to medical care. We did not include disability adjustment because we assume that there is rapid progression to death in the refugee population.

\section{Conclusions}

HepB BD vaccination is very cost-effective across three SSA refugee populations. Regular reporting of BD vaccination rates by humanitarian agencies will help to demonstrate the benefits accrued. This analysis shows the benefit of HepB BD vaccination among camp-based refugee populations and should be implemented in other refugee camps as other more AFR countries introduce national HepB BD policies by 2020 and thereby add to strengthen the overall global health security among these mobile, vulnerable populations [54].

\section{Abbreviations}

AFR: African Region; HBsAg: hepatitis B virus surface antigen; HBV: hepatitis B virus; HCC: hepatocellular carcinoma; Hep B BD: hepatitis B vaccine birth dose; HIV: human immunodeficiency virus; ICER: incremental costeffectiveness ratio; LY: life year; RDT: rapid diagnostic test; RI: routine immunization; SSA: Sub-Saharan Africa; UNICEF: United Nations Children's Fund; USD: United States dollars; WHO: World Health Organization

\section{Funding}

This work was supported by the Duke Emergency Medicine Global Health Grant.

\section{Availability of data and materials}

All data are available through the sources listed in the references section.

\section{Disclaimer}

The findings and conclusions in this study are those of the author(s) and do not necessarily represent the official position of the Centers for Disease Control and Prevention.

\section{Authors' Contributions}

EKL and STC conceived of the study. JMR and STC acquired, analyzed and interpreted the data. JN and SO provided technical assistance in modelling. CWW and CAS provided critical manuscript revisions. All authors approved the final manuscript for publication.

\section{Ethics approval}

This statistical simulation did not involve human subjects.

\section{Consent for publication}

Not applicable.

\section{Competing interests}

The authors declare that they have no competing interests.

\section{Publisher's Note}

Springer Nature remains neutral with regard to jurisdictional claims in published maps and institutional affiliations.

\section{Author details}

'Department of Emergency Medicine, Greenville Health System, 701 Grove Rd, Greenville, SC 29605, USA. ${ }^{2}$ Division of Viral Hepatitis, United States Centers for Disease Control and Prevention, 1600 Clifton Rd, Atlanta, GA 30329, USA. ${ }^{3}$ Division of Global Migration and Quarantine, United States Centers for Disease Control and Prevention, 1600 Clifton Rd, Atlanta, GA 30329, USA. ${ }^{4}$ Division of Global Health Protection, United States Centers for Disease Control and Prevention, 1600 Clifton Rd, Atlanta, GA 30329, USA. ${ }^{5}$ Division of Emergency Medicine, Duke University Medical Center, DUMC Box 3096, 2301 Erwin Road, Durham, NC 27701, USA. ${ }^{6}$ Emergency Response and Recovery Branch, Division of Global Health Protection, United States Centers for Disease Control and Prevention, 1600 Clifton Rd, Atlanta, GA 30329, USA.

Received: 16 July 2018 Accepted: 12 February 2019

Published online: 26 February 2019

\section{References}

1. World Health Organization. Hepatitis B [https://www.who.int/en/newsroom/fact-sheets/detail/hepatitis-b].

2. World Health Organization: Preventing perinatal hepatitis B virus transmission: A guide for introducing and strengthening hepatitis B birth dose vaccination. Department of Immunization, Vaccines and Biologicals 2015.

3. Ekra D, Herbinger K-H, Konate S, Leblond A, Fretz C, Cilote V, Douai C, Da Silva A, Gessner BD, Chauvin P. A non-randomized vaccine effectiveness trial of accelerated infant hepatitis B immunization schedules with a first dose at birth or age 6 weeks in Côte d'Ivoire. Vaccine. 2008;26(22):2753-61.

4. World Health Organization. Hepatitis B vaccines. Weekly Epid Record. 2009; 84(40):405-20.

5. Rossi C, Shrier I, Marshall L, Cnossen S, Schwartzman K, Klein MB, Schwarzer $G$, Greenaway C. Seroprevalence of chronic hepatitis B virus infection and prior immunity in immigrants and refugees: A systematic review and metaanalysis. PLoS One. 2012;7(9):e44611.

6. Médecins Sans Frontières: Refugee health: An approach to emergency situations: Macmillan; 1997.

7. Vaccination in acute humanitarian emergencies: a framework for decision making [http://www.who.int/immunization/research/meetings_workshops/ 5_SAGE_PDVAC_2015.pdf].

8. WHO Regional Strategic Plan for Immunization 2014-2020 [https://afro.who. int/publications/regional-strategic-plan-immunization-2014-2020-0].

9. Global policy report on the prevention and control of viral hepatitis [http:// global-report.worldhepatitisalliance.org/files/global_report/download/HEP_ GlobalReport_web.pdf].

10. Country operations profile - Djibouti [http://www.unhcr.org/pages/ 49e483836.html].

11. Mauritania: UNHCR Operational Update [https://reliefweb.int/report/ mauritania/mauritania-unhcr-operational-update-15-september-2017-enar].

12. Country operations profile - Algeria [http://www.unhcr.org/50a9f8260.pdf].

13. Worldwide protracted Refugee and IDP populations [http://www. migrationpolicycentre.eu/worldwide-protracted-refugee-idp-populations/].

14. Lu SQ, McGhee SM, Xie X, Cheng J, Fielding R. Economic evaluation of universal newborn hepatitis B vaccination in China. Vaccine. 2013;31(14): 1864-9.

15. WHO. Immunization Coverage. Immunizations, Vaccines and Biologicals, 2017. Available from: http://www.who.int/immunization/en.

16. Immunization Coverage [http://www.who.int/immunization/monitoring surveillance/routine/coverage/en/index4.html].

17. Boulaajaj K, Elomari Y, Elmaliki B, Madkouri B, Zaid D, Benchemsi N. Prevalence of hepatitis $C$, hepatitis B and HIV infection among haemodialysis patients in Ibn-Rochd university hospital Casablanca. Nephrol Ther. 2005;1(5):274-84.

18. Maiga YI, Gassin M, Rhaly AA, Pillot J, Marjolet M, Morel D, Dicko K, Dicko I. Prevalence of hepatitis B virus in women of childbearing age in Mali. Bull Soc Pathol Exot. 1990;83(1):93-9.

19. Mauritania | Global Focus. [http://reporting.unhcr.org/mauritania].

20. World Population Data Sheet [https://www.prb.org/2015-world-populationdata-sheet/].

21. Tan-Torres Ejeder T, Baltussen R, Adam T, Hutubessy R, Acharya A, Evans DB. Making choices in health: WHO guide to cost-effectiveness analysis. Geneva: World Health Organization; 2003. 
22. Lo ASF, McMahon BJ. Chronic hepatitis B. Hepatology. 2007:45(2):507-39.

23. D'Amico G, Morabito A, Pagliaro L, Marubini E. Survival and prognostic indicators in compensated and decompensated cirrhosis. Digest Dis Sci. 1986;31(5):468-75.

24. Beasley RP, Lin C-C, Wang K-Y, Hsieh F-J, Hwang L-Y, Stevens C, Sun T-S, Szmuness W. Hepatitis B immune globulin (HBlg) efficacy in the interruption of perinatal transmission of hepatitis B virus carrier state. Lancet. 318(8243):388-93.

25. Fan L, Owusu-Edusei K, Schillie SF, Murphy TV. Cost-Effectiveness of Testing Hepatitis B-Positive Pregnant Women for Hepatitis B e Antigen or Viral Load. Obstet Gynecol. 2014;123(5):929-37.

26. Kim S-Y, Salomon JA, Goldie SJ. Economic evaluation of hepatitis B vaccination in low-income countries: using cost-effectiveness affordability curves. Bull World Health Org. 2007:85(11):833-42.

27. Nayeri UA, Werner EF, Han CS, Pettker CM, Funai EF, Thung SF. Antenatal lamivudine to reduce perinatal hepatitis B transmission: a cost-effectiveness analysis. Am J Obs Gyne. 2012;207(3):231.e231-7.

28. World Health Organization. Life tables by country [http://apps.who.int/gho/ data/view.main.61530?lang=en].

29. World Bank. Life expectancy at birth, total (years) [http://data.worldbank.org/ indicator/SP.DYN.LEO0.IN].

30. Marion SA, Pastore MT, Pi DW, Mathias RG. Long-term Follow-up of Hepatitis B Vaccine in Infants of Carrier Mothers. Am J Epid. 1994;140(8):734-46.

31. Gavi. Hepatitis B vaccine at birth - GAVI responds to MSF [http://www.gavi. org/Library/News/Statements/2014/Hepatitis-B-vaccine-at-birth-GAVIresponds-to-MSF/].

32. Shivkumar $S$, Peeling $R$, Jafari $Y$, Joseph $L$, Pai NP. Rapid point-of-care firstline screening tests for hepatitis B infection: a meta-analysis of diagnostic accuracy (1980-2010). Am J Gastroenterology. 2012;107(9):1306-13.

33. World Health Organization. Reported estimates of HepB birth dose coverage [http://apps.who.int/immunization_monitoring/globalsummary/ timeseries/tscoveragehepb\%5Fbd.html].

34. Mast EE, Margolis HS, Fiore AE, Brink EW, Goldstein ST, Wang SA, Moyer LA, Bell BP, Alter MJ. A comprehensive immunization strategy to eliminate transmission of hepatitis B virus infection in the United States. MMWR. 2005; 54(16):1-32.

35. Stevens CE, Beasley RP, Tsui J, Lee W-C. Vertical transmission of hepatitis B antigen in Taiwan. NEJM. 1975;292(15):771-4.

36. Wong VCW, Reesink HW, Ip HMH, Lelie PN, Reerink-Brongers EE, Yeung CY, Ma HK. Prevention of the HBsAg carrier state in newborn infants of mothers who are chronic carriers of $\mathrm{HBsAg}$ and $\mathrm{HBeAg}$ by administration of hepatitis-B vaccine and hepatitis-B immunoglobulin double-blind randomised placebo-controlled study. Lancet. 1984;323(8383):921-6.

37. Fattovich G, Giustina G, Schalm SW, Hadziyannis S, Sanchez-Tapias J, Almasio P, Christensen E, Krogsgaard KIM, Degos F, de Moura MC, et al. Occurrence of hepatocellular carcinoma and decompensation in Western European patients with cirrhosis type B. Hepatology. 1995;21(1):77-82.

38. De Jongh FE, Janssen HLA, De Man RA, Hop WCJ, Schalm SW, Van Blankenstein M. Survival and prognostic indicators in hepatitis B surface antigen-positive cirrhosis of the liver. Gastroenterology. 1992;103(5):1630-5.

39. Stanaway JD, Flaxman AD, Naghavi M, Fitzmaurice C, Vos T, Abubakar I, Abu-Raddad LJ, Assadi R, Bhala N, Cowie B, et al. The global burden of viral hepatitis from 1990 to 2013: findings from the Global Burden of Disease Study 2013. Lancet. 2016;388(10049):1081-8.

40. Suchy FJ, Sokol RJ, Balistreri WF. Liver disease in children: Cambridge University Press; 2014.

41. UNAIDS. Countries: HIV and AIDS estimates [http://www.unaids.org/en/ regionscountries/countries]

42. Merrill RM, Hunter BD. Seroprevalence of markers for hepatitis B viral infection. Int J Infect Dis. 2011:15(2):e78-e121.

43. World Health Organization. Reported estimates of HepB 3-dose coverage. In: Vaccines monitoring system; 2015.

44. Brenzel L, Young D, Walker DG. Costs and financing of routine immunization: Approach and selected findings of a multi-country study (EPIC). Vaccine. 2015;33(Supplement 1):A13-20.

45. World Bank: GDP per capita, PPP, 1990-2015. 2017

46. Hutubessy R, Chisholm D, Edejer TT-T. Generalized cost-effectiveness analysis for national-level priority-setting in the health sector. Cost Effectiveness and Resource Allocation. 2003;1(1):8.

47. Klingler C, Thoumi Al, Mrithinjayam VS. Cost-effectiveness analysis of an additional birth dose of Hepatitis B vaccine to prevent perinatal transmission in a medical setting in Mozambique. Vaccine. 2012;31(1):252-9.
48. Tilson L, Thornton L, O'Flanagan D, Johnson H, Barry M. Cost effectiveness of hepatitis B vaccination strategies in Ireland: an economic evaluation. Europ J Pub Health. 2008;18(3):275-82.

49. UN High Commissioner for Refugees. Resettlement: A new beginning in a third country [http://www.unhcr.org/pages/4a16b1676.html].

50. Andrus JK, Fitzsimmons J. Introduction of new and underutilized vaccines: Sustaining access, disease control, and infrastructure development. PLoS Med. 2005;2(10):e286.

51. World Health Organization. Global vaccine action plan [http://www.who.int/ iris/bitstream/10665/78141/1/9789241504980_eng.pdf].

52. Schweitzer A, Horn J, Mikolajczyk RT, Krause G, Ott JJ. Estimations of worldwide prevalence of chronic hepatitis B virus infection: a systematic review of data published between 1965 and 2013. Lancet 2015;386(10003): 1546-1555.

53. Kim S-Y, Billah K, Lieu TA, Weinstein MC. Cost effectiveness of hepatitis B vaccination at HIV counseling and testing sites. Am J Prev Medicine 2006; 30(6):498-506.e496.

54. UNICEF Supplies and Logistics. Hepatitis B Vaccine Price Data. 2017. Available from: https://www.unicef.org/supply/index_57476.html.

55. Gish RG, Gutierrez JA, Navarro-Cazarez N, Giang K, Adler D, Tran B, et al. A simple and inexpensive point-ofcare test for hepatitis B surface antigen detection: serological and molecular evaluation. J Viral Hepatitis 2014;21(12): 905-908.
Ready to submit your research? Choose BMC and benefit from:

- fast, convenient online submission

- thorough peer review by experienced researchers in your field

- rapid publication on acceptance

- support for research data, including large and complex data types

- gold Open Access which fosters wider collaboration and increased citations

- maximum visibility for your research: over $100 \mathrm{M}$ website views per year

At BMC, research is always in progress.

Learn more biomedcentral.com/submissions 